\title{
Numerical Modeling of Single-Chamber SOFCs with Hydrocarbon Fuels
}

\author{
Y. Hao* and D. G. Goodwin**
}

Division of Engineering and Applied Science, California Institute of Technology, Pasadena, California 91125, USA

\begin{abstract}
A two-dimensional numerical model of a single-chamber solid oxide fuel cell (SCFC) operating on hydrocarbon fuels is developed. The SCFC concept is a simplification of a conventional solid oxide fuel cell in which the anode and cathode are both exposed to the same premixed fuel-air mixture, and selective catalysts promote electrochemical oxidation of the fuel at the anode and simultaneous electrochemical oxygen reduction at the cathode. Optimization of SCFC stacks requires considering complex, coupled chemical and transport processes. The model accounts for the coupled effects of gas channel fluid flow, heat transfer, porous media transport, catalytic reforming-shifting chemistry, electrochemistry, and mixed ionic-electronic conductivity. It solves for the velocity, temperature, and species distributions in the gas, profiles of gaseous species and coverages of surface species within the porous electrodes, and the current density profile in an SCFC stack for a specified electrical bias. The model is general, and can be used to simulate any electrode processes for which kinetics are known or may be estimated. A detailed elementary mechanism is used to describe the reactions over the anode catalyst surface. Different design alternatives including yttria-stabilized zirconia vs $\mathrm{Ce}_{0.8} \mathrm{Sm}_{0.2} \mathrm{O}_{19}$ electrolytes, the effects of mixed conductivity, and the optimal fuel-to-air ratio are explored. (C) 2006 The Electrochemical Society. [DOI: 10.1149/1.2404895] All rights reserved.
\end{abstract}

Manuscript submitted August 15, 2006; revised manuscript received September 27, 2006

Available electronically December 22, 2006.

A single-chamber fuel cell (SCFC) is one in which the anode and cathode are both exposed to the same premixed fuel-air stream, and selective electrocatalysts are used to preferentially oxidize the fuel at the anode and reduce oxygen at the cathode. The latest studies of SCFCs demonstrate great improvements in power density and reduction in operating temperature with innovations in material and system design. ${ }^{1-4}$ While the efficiency is typically lower than that of conventional dual-chamber solid oxide fuel cells (SOFCs), SCFCs do not require seals, and allow a very simple gas manifold design. For some applications, notably small-scale power generation, the mechanical simplicity of an SCFC design may make it more attractive than a dual-chamber SCFC, even with a lower efficiency.

The need for selective electrocatalysts has several implications for the design of an SCFC. First, an SCFC must operate at a temperature low enough that the catalysts maintain some degree of selectivity; this typically limits the temperature to below $700^{\circ} \mathrm{C}$, which is significantly lower than that of conventional SCFCs with an yttria-stabilized zirconia (YSZ) electrolyte. For this reason, SCFCs demonstrated to date have used ceria-based electrolytes, rather than YSZ.

Another implication of the need for selective electrocatalysts is that an SCFC is unlikely to run well, if at all, on hydrogen. Any catalyst that promotes electrochemical oxidation of hydrogen, or electrochemical reduction of oxygen, would very likely promote direct catalytic combustion if exposed to a hydrogen-air mixture. This problem can be dealt with by using a hydrocarbon fuel instead of hydrogen, as has been done in all successful demonstrations of SCFC operation. With a hydrocarbon fuel, catalytic partial oxidation and reforming chemistry can be used within the anode to deplete incoming oxygen, creating a reducing environment deep within the anode near the electrochemically active layer, and to generate hydrogen needed for the electrochemistry in situ, very near where it is consumed in the electrochemical oxidation reaction. Similarly, at the cathode, if hydrogen generation via hydrocarbon cracking can be suppressed, parasitic combustion at the cathode may be minimized.

Methane and higher hydrocarbons such as ethane, propane, butane, and liquid petroleum gas have all been demonstrated to be potential fuels for an SCFC. ${ }^{1-6}$ Hibino et al. ${ }^{1}$ have reported achieving a power density of $650 \mathrm{~mW} / \mathrm{cm}^{2}$ at a temperature as low as $550^{\circ} \mathrm{C}$ using a $\mathrm{Ni}-\mathrm{Ce}_{0.8} \mathrm{Sm}_{0.2} \mathrm{O}_{1.9}$ (Ni-SDC) cermet anode and a $\mathrm{Sm}_{0.5} \mathrm{Sr}_{0.5} \mathrm{CoO}_{3}$ (SSC) cathode and methane as the fuel. Shao et al. ${ }^{2}$

* Electrochemical Society Student Member.

** Electrochemical Society Active Member. have achieved a power output of $350 \mathrm{~mW}$ using a thermally selfsustaining two-cell stack at $585^{\circ} \mathrm{C}$ with a $\mathrm{Ni}-\mathrm{SDC}$ anode, a $\mathrm{Ba}_{0.5} \mathrm{Sr}_{0.5} \mathrm{Co}_{0.8} \mathrm{Fe}_{0.2} \mathrm{O}_{3}$ (BSCF) cathode, and propane as the fuel.

Although very respectable power densities have been demonstrated experimentally, it is not at all clear that present designs are close to optimal, or that the measured performance for a single cell translates to performance in a stack. For example, hydrogen generated within one anode might diffuse to the cathode of an adjacent cell, where it burns, or if some cells are placed downstream of others, depletion of fuel or oxygen may strongly affect performance.

Assessing the potential performance of an SCFC stack design requires considering these complex effects of gas flow, diffusion, and depletion. This, in turn, requires a numerical model that can treat the flow and species transport in the gas between cells, fully coupled to the chemistry, electrochemistry, and porous media transport within the electrodes of each cell.

The problem is more complex than encountered when simulating dual-chamber configurations, where the flow in the gas channels may be treated as a plug flow. ${ }^{7}$ In the absence of defined gas channels, the flow and transport processes must be treated using a multidimensional formulation. In this paper, we present a twodimensional numerical model of an SCFC running on hydrocarbon fuels.

\section{SCFC Operation}

Figure 1 shows the operation of a single cell consisting of a thin dense, solid oxide electrolyte layer sandwiched between two porous electrodes (known as stacked SCFC). Surface reactions over the anode catalyst supply $\mathrm{H}_{2}$ and $\mathrm{CO}$ for the electrochemical reactions. A fuel-rich gas mixture is required to produce $\mathrm{CO}$ and $\mathrm{H}_{2}$ without producing significant amounts of $\mathrm{CO}_{2}$ and $\mathrm{H}_{2} \mathrm{O}$.

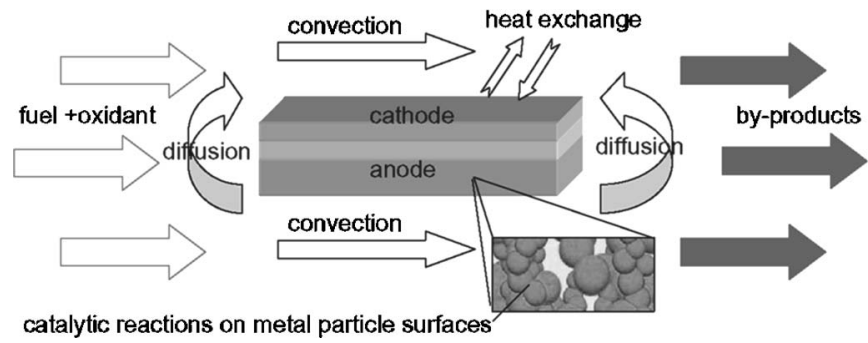

Figure 1. Operation of a stacked SCFC. 


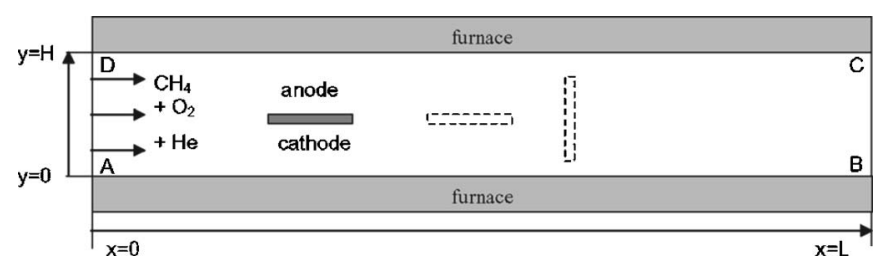

Figure 2. Simulation geometry for a single cell. Dashed lines represent the situation for multiple cells; $L$ : channel length; $H$ : channel height.

The cell in this study is anode supported. For hydrocarbon fuels, this structure has some advantages in that the electron-carrying metal (typically $\mathrm{Ni}$ ) can also serve as a reforming or catalytic partial oxidation (CPOX) catalyst. ${ }^{8}$ In such a system the anode is usually on the order of $1 \mathrm{~mm}$ thick, while the thicknesses of the cathode and the electrolyte are only a few tens of $\mu \mathrm{m} .^{8}$

Although YSZ is the most frequently used electrolyte material for an SOFC, it is unlikely to be used at temperatures below $700^{\circ} \mathrm{C}$ due to significant ohmic loss, and alternative materials such as ceriabased or lanthanum gallate oxides should be used because of their much higher ionic conductivities. ${ }^{4}$ Operation at reduced temperature also causes significant polarization losses at the electrodes. Ni-ceria cermets and Co-based perovskite oxides have been generally regarded as suitable anodes and cathodes, respectively. ${ }^{4}$

\section{Model}

The computational domain is the rectangular region $\mathrm{ABCD}$ in Fig. 2. One membrane electrode assembly (MEA) is placed in a rectangular gas channel of length $\mathrm{L}$ and height $\mathrm{H}$. Configurations either parallel or perpendicular to the axial direction are allowed, and multiple MEAs are allowed in the same gas channel. The top and bottom walls of the channel are assumed to have a constant temperature, which corresponds to a furnace in actual experiments. The mixture of fuel, oxygen, and carrier gas comes in from the inlet on the left. In this study, we used methane as the fuel and helium as the inert carrier gas.

The model consists of several modules (submodels) that handle different regions of the computational domain, including flow in the gas channel, flow and catalytic reaction in the porous electrodes, electrochemistry at the electrode-electrolyte interfaces, mixed conductivity of the electrolyte, and the thermal effects of the fuel cell. In particular, the electrical performance of each cell and interaction among the cells at steady state are simulated by solving the coupled partial differential equations described below.

The model currently only simulates the stacked SCFC. The striped SCFC, which attaches two electrodes on the same side of the electrolyte, requires more complicated calculation of the flow field and current, and so cannot be treated in the framework of this model.

The gas channel flow model.- The flow model determines the two-dimensional velocity, density, temperature, and species mass fraction fields in the gas surrounding the cells. It is coupled to a separate model for the transport and reaction processes within the cell (described below) at the gas-cell interfaces. The gas is modeled as an ideal gas mixture of species with homogeneous chemistry neglected. Gupta et al. ${ }^{9}$ reported that at temperatures below $800^{\circ} \mathrm{C}$ and residence time of a few seconds, only a few percent of the methane fuel is reacted in homogeneous reactions. Walters et al. ${ }^{10}$ have shown through simulation that the temperature needs to approach $900^{\circ} \mathrm{C}$ for gas-phase chemistry to play a substantial role for SOFCs using natural gas as a fuel.

A zero Mach number, variable-density formulation of the conservation equations is used. The zero Mach number assumption applies to situations where the velocities are low (compared to the sound speed) but does not truly mean the flow speed is zero. It decouples density from pressure and eliminates the acoustic Courant-
Friedrich-Levy (CFL) restriction on time step size, which is a condition for the stability of an explicit finite difference discretization of the partial differential equations that describe compressible fluid flows, and can put severe restrictions on the maximum allowable time step size. ${ }^{11}$ For fuel cell applications, the assumption of zero Mach number is very good because typical gas velocities are less than $1 \mathrm{~m} / \mathrm{s}$, in order to provide sufficient residence time to complete the electrochemical oxidation process. The density variation results from the spatial variation of the chemical composition (and therefore mean molecular weight), as well as the temperature of the gas, but not from the finite Mach number. Accordingly, the pressure in the gas channel is nearly constant (e.g., $1 \mathrm{~atm})$. However, the pressure gradient must be considered when the velocity field is computed. This is consistent with the constant-pressure assumption, because the pressure variation in the channel (typically $\sim 10^{-2} \mathrm{~Pa}$ ) is negligible compared with the pressure itself $\left(\sim 10^{5} \mathrm{~Pa}\right)$. The velocity field $u$ is determined from the continuity equation

$$
\frac{\partial \rho}{\partial t}+\nabla \cdot(\rho \underline{u})=0
$$

and the momentum equation

$$
\frac{\partial \rho \underline{u}}{\partial t}+\nabla \cdot(\rho \underline{u u})=-\nabla p-\frac{2}{3} \nabla(\mu \nabla \cdot \underline{u})+\nabla \cdot\left[\mu\left(\nabla \underline{u}+(\nabla \underline{u})^{T}\right)\right]
$$

with the density determined by the ideal gas equation of state

$$
\rho=\frac{p_{0} \bar{W}}{R T}, \quad R=8.314 \mathrm{~J} \mathrm{~mol}^{-1} \mathrm{~K}^{-1}
$$

where $p_{0}$ is the atmospheric pressure, $\bar{W}$ is mean molecular weight, $T$ is the absolute temperature, $t$ is time, $p$ is pressure, and $\mu$ is dynamic viscosity. The term $(\nabla \underline{u})^{T}$ is the transpose of the velocity gradient tensor $\nabla \underline{u}$. The temperature distribution is obtained by solving the energy equation

$$
\frac{\partial \rho T}{\partial t}+\nabla \cdot(\rho \underline{u} T)=\frac{1}{c_{p}} \nabla \cdot(\lambda \nabla T)-\frac{1}{c_{p}} \sum_{k=1}^{K} c_{p k} D_{k m} \nabla Y_{k} \cdot \nabla T
$$

where $\lambda$ is the thermal conductivity, $c_{p}$ and $c_{p k}$ are the specific heat at constant pressure for the gas mixture and for species $k$, respectively, $D_{k m}$ is the mixture-averaged diffusion coefficient for species $k$ relative to the rest of the multicomponent mixture, and $K$ is the total number of gas-phase species. The species mass fractions $Y_{k}(k=1, \ldots, K)$ are determined from the species mass conservation equation

$$
\frac{\partial\left(\rho Y_{k}\right)}{\partial t}+\nabla \cdot\left(\rho \underline{u} Y_{k}+\rho D_{k m} \nabla Y_{k}\right)=0
$$

Equation 5 applies when the variation of mean molecular weight is small, e.g., with a large excess of inert gas, which is usually the case for SCFC operation in the experimental literature (with air or with helium). If the variation of mean molecular weight is large, an additional term involving both the pressure gradient and mean molecular weight is needed on the left-hand side.

Boundary conditions for governing equations $1,2,4$, and 5 are listed in Table I. Discretization and integration of the equations are performed using the SIMPLEC algorithm. ${ }^{12}$ The spatial derivatives are discretized using a second-order accurate approximation, and the equations are integrated over a control volume of width $\Delta x$ and height $\Delta y$ using the finite volume approach. A staggered grid is used on the computation domain, with scalars defined at the center and vector components at the faces of a control volume. ${ }^{12}$ Physical properties such as viscosity, heat capacity, and diffusion coefficient of the gas mixture are calculated at every grid point using the temperature and composition from the previous time step. The equations are marched in time until steady-state solution is obtained. The model can simulate SCFC performance with or without solving the energy Eq. 4. 


\begin{tabular}{|c|c|c|c|c|}
\hline & $u$ & $v$ & $Y_{k}$ & $T$ \\
\hline Inlet & $u_{\text {in }}$ & $v=0$ & $\underline{n} \times\left(\rho Y_{k} \underline{u}+\underline{j_{k}}\right)=\rho_{\text {in }} u_{\text {in }} Y_{k, \text { in }}$ & $T_{\text {in }}$ \\
\hline Outlet & $\frac{d u}{d x}=0$ & $\frac{d v}{d x}=0$ & $\underline{n} \times \underline{j_{k}}=0$ & $\frac{d T}{d x}=0$ \\
\hline $\begin{array}{l}\text { Top and } \\
\text { bottom } \\
\text { walls }\end{array}$ & $u=0$ & $v=0$ & $\frac{d Y_{k}}{d y}=0$ & $T_{\text {furnace }}$ \\
\hline $\begin{array}{c}\text { MEA } \\
\text { surface }\end{array}$ & $u=0$ & same as $Y_{k}$ & $\underline{n} \times\left(\rho Y_{k} \underline{u}+\underline{j_{k}}\right)=\dot{s}_{k} W_{k}$ & $T_{\text {cell }}(x)$ \\
\hline
\end{tabular}

The porous electrode transport model.-In order to determine the gas composition at the electrode-electrolyte interface, where the electrochemistry is assumed to take place, it is necessary to compute the coupled problem of transport and reaction within the porous electrodes. Gaseous reactions are neglected and only reactions occurring on the catalyst particle surfaces are considered, due both to the low temperature and to the small pore size, comparable to the mean free path for the molecular species.

The porous electrode model is formulated in terms of the gaseous species of the flow model, and in addition a set of adsorbed surface species on the catalyst particle surfaces with which the gaseous species may react. The mass concentrations $\rho_{k}(k=1, \ldots, K)$ of the gaseous species in the pores are determined by solving the porousmedia gaseous species conservation equation

$$
\nabla \cdot j_{k}=A_{c} W_{k} \dot{s}_{k}, \quad k=1, \ldots, K
$$

where $\boldsymbol{j}_{k}, W_{k}$, and $\dot{s}_{k}$ are the diffusive mass flux, molecular weight, and molar production rate on the catalyst surface of species $k$, respectively, $A_{c}$ is the volumetric specific surface area of the catalyst, and $K$ is the number of gaseous species. The mass flux $\boldsymbol{j}_{k}$ depends on the gradient of $\rho_{k}$, and is evaluated by the dusty-gas model (DGM). ${ }^{13}$ The DGM used in this study accounts for the major mechanisms for gaseous molecular transport in porous media including bulk molecular diffusion, Knudsen diffusion, and Darcy flow. ${ }^{13,14}$ Zhu et al. ${ }^{7}$ have discussed the application of this model to an SOFC anode in detail.

The coverage fractions (or coverages) $\theta_{k}\left(k=1, \ldots, K_{s}\right)$ of the surface species are computed self-consistently with the gaseous species, by requiring that the surface species are all in steady state, and therefore their net chemical production rates are zero

$$
\dot{s}_{k}=0, \quad k=1, \ldots, K_{s}
$$

where $K_{s}$ is the total number of surface species, and $\dot{s}_{k}$ is supplied by the heterogeneous chemistry mechanism (for the anode) that is discussed shortly.

The electrode submodel is formulated as a steady-state model, even though the flow model, to which it is coupled, is formulated in a time-dependent form. This formulation is advantageous, because the inclusion of fast reactions would otherwise make the system of Eq. 6 and 7 stiff, and would require very small time steps and long computation times. Because only the steady-state solution is of interest, there is no error introduced by this procedure. The steadystate model allows solving Eq. 6 and 7 fully implicitly using the damped Newton's method for stiff systems. Given the mass fractions of the gaseous species at the electrode-gas interface, it solves for the steady-state species fluxes through the electrode and surface coverages. The computed fluxes at the electrode-gas interface are fed back to the flow model, where they are incorporated into the discretized species conservation equations as boundary conditions, and the interface velocity $u$ or $v=\Sigma_{k=1}^{K} j_{k} / \rho$ is used as the boundary condition for the momentum Eq. 2.
Heterogeneous chemistry.- For the calculations presented here, we used an elementary multistep reaction mechanism ${ }^{7}$ that accounts for the partial oxidation and steam reforming of methane over a $\mathrm{Ni}$ surface. The mechanism consists of 46 heterogeneous reactions between 6 gaseous species and 13 adsorbed surface species. The mechanism is designed for typical SOFC operating conditions (temperature and gas components) and has been validated by Hecht et al. experimentally. ${ }^{15}$ However, this mechanism is not designed to predict coking, where the concentration of oxygen in the gas channel is so low that carbon deposits over the anode catalyst surface. In this study, we consider only fuel-to-oxygen ratios for which coking is not a problem.

For the cathode, we use a global mechanism of methane full oxidation over $\mathrm{Ba}_{0.5} \mathrm{Sr}_{0.5} \mathrm{Co}_{0.8} \mathrm{Fe}_{0.2} \mathrm{O}_{3-\delta}$ (BSCF) described in our previous work. ${ }^{16}$ We found that carbon-bearing products were almost entirely $\mathrm{CO}_{2}$, and the reaction rate of methane to $\mathrm{CO}_{2}$ was fit to the expression $r=k \times P_{\mathrm{CH}_{4}}^{m} \times P_{\mathrm{O}_{2}}^{n}$, where the rate constant $k=k_{0} \exp \left(-E_{a} / R T\right)$, and the exponents $m$ and $n$ were found to be independent of temperature. The oxidation rates of hydrogen and carbon monoxide over the BSCF catalyst surface were not measured and the oxidation reactions are assumed to be instantaneous, because both species are present in the cathode due to gas diffusion in the channel flow from the anode side of the cell, and their concentrations are much lower than that of methane.

The electrochemistry model.- This model computes the current density as a function of distance $x$ from the MEA leading edge given the load potential. It makes the following assumptions. First, electrochemical reactions take place only at the electrode-electrolyte interfaces and are treated as boundary conditions for the porous transport module below. Second, the flow of oxygen-ion current through the electrolyte is assumed to be one-dimensional, across the electrolyte from the anode to the cathode. Third, the electrochemistry consists only of the reduction of atmospheric oxygen at the cathode, and the oxidation of hydrogen at the anode. Although $\mathrm{H}_{2}$ and $\mathrm{CO}$ are both electrochemically active fuels, there is strong evidence that on the anode side, $\mathrm{H}_{2}$ dominates the charge-transfer chemistry, and water-gas-shift chemistry replenishes the $\mathrm{H}_{2}$ via reaction of $\mathrm{CO}$ with the $\mathrm{H}_{2} \mathrm{O}$ that is a product of the $\mathrm{H}_{2}$ charge transfer. ${ }^{17}$ Finally, the fourth point is, the ohmic resistance of the electrodes is negligible.

With these assumptions, the relationship between current density and potential difference can be derived. For pure ionic conductor electrolytes such as YSZ, the current density is of course ionic, and a detailed discussion can be found in Ref. 18. For mixed ionic and electronic conductor electrolytes that is discussed shortly, the derivation of the ionic current in Ref. 18 still applies. In this paper, we use subscripts " $i$ " and " $e$ " to denote "ionic" and "electronic," respectively. The ionic current density $i_{i}(x)$ is obtained from

$$
E=E^{0}-\frac{L_{e} i_{i}}{\sigma_{i}(T)}-\eta_{\text {act }, c}\left(i_{i}\right)-\eta_{\text {act }, a}\left(i_{i}\right)
$$

by Newton iteration with charge-transfer overpotentials $\eta_{\text {act, }, a}$ and $\eta_{\text {act }, c}$ at the electrode-electrolyte interfaces obtained by solving the Butler-Volmer equation

$$
i_{i}=i_{0}\left[\exp \left(\alpha_{a} \eta_{\text {act }} f\right)-\exp \left(-\alpha_{c} \eta_{\text {act }} f\right)\right], \quad f=F /(R T)
$$

at the anode- and cathode-electrolyte interfaces, respectively. Here, $L_{e}$ is the electrolyte thickness, $\sigma_{i}(T)$ is the electrolyte ionic conductivity, $E$ is the load potential, and $E^{0}$ is the Nernst potential defined by

$$
E^{0}=-\frac{\Delta G^{0}}{2 F}+\frac{R T}{2 F} \ln \frac{p_{\mathrm{H}_{2}} p_{\mathrm{O}_{2}}^{1 / 2}}{p_{\mathrm{H}_{2} \mathrm{O}}}
$$

where $\Delta G^{0}$ is the standard free energy of the reaction $\mathrm{H}_{2}$ $+\frac{1}{2} \mathrm{O}_{2} \rightleftharpoons \mathrm{H}_{2} \mathrm{O}$, and the partial pressures $p_{\mathrm{H}_{2}}$ and $p_{\mathrm{H}_{2} \mathrm{O}}$ are evaluated at the anode-electrolyte interfaces solved from the porous electrode transport model, while $p_{\mathrm{O}_{2}}$ is evaluated at the cathode- 
electrolyte interface obtained in the same way. As for other symbols in the equations above, $i_{0}$ is the exchange current density, $\alpha_{a}$ and $\alpha_{c}$ are the anodic and cathodic asymmetry factors for each of the electrodes, $F$ is Faraday's constant, and $R$ is the universal gas constant. Compared with other parameters, $\alpha_{a}$ and $\alpha_{c}$ are relatively more difficult to measure by experiment. In our model, they are treated as free-fitting parameters. For charge-transfer processes that include more than one step, the values of the asymmetry factors can be greater than $1 .^{7}$

The exchange current density $i_{0}$ generally depends on the local composition at the electrode. In this study, we use the formulations derived in Ref. 7. For cathode oxygen reduction

$$
i_{0, c}=i_{\mathrm{O}_{2}}^{*} \frac{\left(p_{\mathrm{O}_{2}, c} / p_{\mathrm{O}_{2}}^{*}\right)^{1 / 4}}{1+\left(p_{\mathrm{O}_{2}, c} / p_{\mathrm{O}_{2}}^{*}\right)^{1 / 2}}
$$

where

$$
p_{\mathrm{O}_{2}}^{*}=A_{\mathrm{O}_{2}} \exp \left(-E_{\mathrm{O}_{2}} / R T\right)
$$

with $i_{\mathrm{O}_{2}}^{*}=2.8 \mathrm{~A} / \mathrm{cm}^{2}, \quad A_{\mathrm{O}_{2}}=4.9 \times 10^{8} \mathrm{~atm}, \quad$ and $E_{\mathrm{O}_{2}}$ $=200 \mathrm{~kJ} / \mathrm{mol}$. The partial pressure $p_{\mathrm{O}_{2}, c}$ is for oxygen at the cathode-electrolyte interface. At the anode, we assume

$$
i_{0, a}=i_{\mathrm{H}_{2}}^{*} \frac{\left(p_{\mathrm{H}_{2}, a} / p_{\mathrm{H}_{2}}^{*}\right)^{1 / 4}\left(p_{\mathrm{H}_{2} \mathrm{O}, a}\right)^{3 / 4}}{1+\left(p_{\mathrm{H}_{2}, a} / p_{\mathrm{H}_{2}}^{*}\right)^{1 / 2}}
$$

where

$$
p_{\mathrm{H}_{2}}^{*}=\frac{A_{\mathrm{des}} \Gamma^{2} \sqrt{2 \pi R T W_{\mathrm{H}_{2}}}}{\gamma_{0}} \exp \left(-\frac{E_{\mathrm{des}}}{R T}\right)
$$

with $i_{\mathrm{H}_{2}}^{*}=8.5 \mathrm{~A} / \mathrm{cm}^{2}, \gamma_{0}=0.01, A_{\text {des }}=5.59 \times 10^{19} \mathrm{~s} \mathrm{~cm}^{2} / \mathrm{mol}$, $\Gamma=2.6 \times 10^{-9} \mathrm{~mol} / \mathrm{cm}^{2}$, and $E_{\text {des }}=88.12 \mathrm{~kJ} / \mathrm{mol}$. Partial pressures $p_{\mathrm{H}_{2}, a}$ and $p_{\mathrm{H}_{2} \mathrm{O}, a}$ are calculated by the porous electrode model and correspond to hydrogen and water at the anode-electrolyte interface, respectively. The use of these electrochemical parameter values, which are not for BSCF (or BSCF-SDC) cathodes, together with a methane oxidation mechanism for BSCF (or BSCF-SDC) is not entirely consistent, but is done to construct a realistic cathode model with physically reasonable parameters from an incomplete set of reported data. Because this paper focuses on presenting a theoretical framework instead of making quantitative comparison with experiments, the exchange current densities 11 and 12 are still helpful in qualitatively studying the mechanistic issues that govern the performance of SCFCs.

Based on the first assumption made at the beginning of this section, the nonzero mass fluxes $j_{k}$ at the electrode-electrolyte interfaces can be computed when $i_{i}(x)$ is known, where $k$ stands for $\mathrm{H}_{2}$, $\mathrm{H}_{2} \mathrm{O}$, or $\mathrm{O}_{2}$. While this assumption is good for the thick anode, it is a simplification for the thin cathode, because it is known that the electrochemically active region extends at least $10 \mu \mathrm{m}$ into the porous electrode. ${ }^{18}$ However, modeling distributed electrochemistry coupled to catalytic chemistry is complex, and beyond the scope of this work. We will address this point in a future publication. At the anode-electrolyte interface

$$
j_{\mathrm{H}_{2}}=-\frac{i_{i}(x) W_{\mathrm{H}_{2}}}{2 F}, \quad j_{\mathrm{H}_{2} \mathrm{O}}=\frac{i_{i}(x) W_{\mathrm{H}_{2} \mathrm{O}}}{2 F}
$$

and at the cathode-electrolyte interface

$$
j_{\mathrm{O}_{2}}=-\frac{j_{i}(x) W_{\mathrm{O}_{2}}}{4 F}
$$

where $W_{k}$ is the molecular weight for species $k$. These fluxes are used as boundary conditions for the porous electrode transport model. The set of Eq. 6-9 is solved simultaneously by Newton iteration.

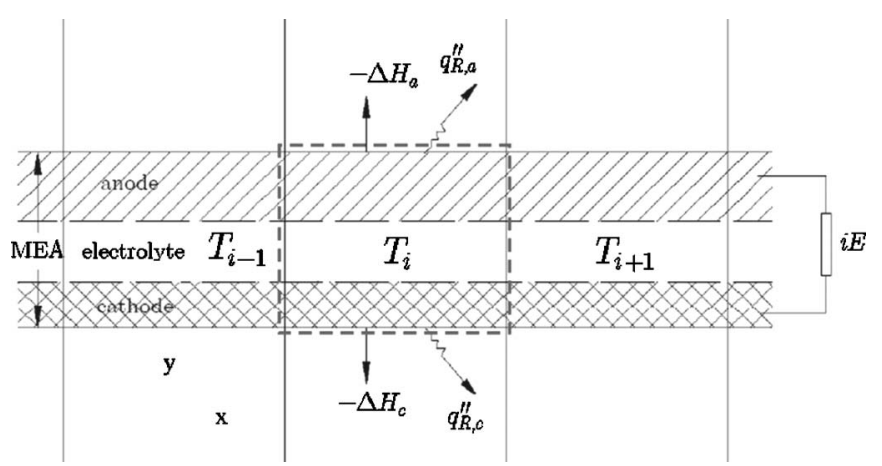

Figure 3. Energy balance over a control volume (dashed line) in the cell. $T$ : cell temperature; $q_{R}^{\prime \prime}$ : radiation heat flux; $\Delta H$ : enthalpy change; $i E$ : power output on external load; subscripts " $a$ " and " $c$ " stand for anode and cathode, respectively.

The mixed ionic-electronic conductor model.- Mixed ionicelectronic conductor (MIECs) are materials that conduct both ionic and electronic charge carriers. ${ }^{19}$ Due to their high ionic conductivity, MIECs have found increasing application as electrolytes in SOFCs operated at reduced temperatures. Hibino et al. reported that ohmic resistances of $\mathrm{La}_{0.9} \mathrm{Sr}_{0.1} \mathrm{Ga}_{0.8} \mathrm{Mg}_{0.2} \mathrm{O}_{3}$ (LSGM) and $\mathrm{Ce}_{0.8} \mathrm{Sm}_{0.2} \mathrm{O}_{1.9}$ (SDC, $0.2 \mathrm{~mm}$ thick, $0.5 \mathrm{~cm}^{2}$ cross-sectional area) are 1.56 and $1.72 \Omega$ at $700^{\circ} \mathrm{C}$, respectively, considerably lower than $2.90 \Omega$ of YSZ, and concluded that LSGM is the most suitable electrolyte for an SCFC. ${ }^{4}$

The model is capable of simulating SCFCs with either pure ionic conductor or MIEC electrolytes. For YSZ, the electrolyte submodel is simple. The ionic conductivity in Eq. 8 has the following form

$$
\sigma_{i}(T)=\frac{\sigma_{0}}{T} \exp \left(-\frac{E_{a}}{R T}\right)
$$

For an MIEC electrolyte, we adopt the model developed by Riess et al. and Gödickemeier et al. ${ }^{20-22}$ However, our formulation is much simpler in that the gas concentrations at the electrode-electrolyte interfaces can be directly obtained from the solution of the porous electrode model, which had to be evaluated through an assumed transport model for the porous electrodes in these references in order to take the concentration overpotential into account correctly. As a result, our description of the MIEC electrolyte employs Eq. 8 and 9 to compute ionic current $i_{i}$, and the electronic current is computed by

$$
i_{e}(x)=-i_{i} \frac{\sigma_{e}\left(p_{\mathrm{O}_{2}}^{C}\right)}{\sigma_{i}(T)} e^{h_{C} f} \frac{e^{E \cdot f}-1}{1-e^{-i_{i} L_{e} f / \sigma_{i}}}
$$

where for the SDC electrolyte of interest here, the electronic conductivity is given by ${ }^{23}$

$$
\sigma_{e}\left(p_{\mathrm{O}_{2}}\right)=k p_{\mathrm{O}_{2}}^{-1 / 4}, \quad k=a T^{-1} e^{-b / T}
$$

Lai et al. ${ }^{23}$ have systematically studied the electronic and ionic transport properties of SDC, based on which we use $a=2.42$ $\times 10^{8} \mathrm{~K}^{-1} \mathrm{~cm}^{-1} \mathrm{~atm}^{0.25}$ and $b=2.69 \times 10^{4} \mathrm{~K}$ for this study. The ionic conductivity $\sigma_{i}$ assumes the form of Eq. 15 . The total current density is the sum of the ionic and electronic currents, i.e.,

$$
i_{\text {tot }}=i_{i}+i_{e}
$$

and is the current output to external circuits.

The conduction and radiation model.- This model predicts the cell temperature, which is a crucial factor for the electrical performance because it dictates reaction rates and electrolyte conductivity. Shao et al. found experimentally that the cell usually runs significantly higher than the furnace temperature. ${ }^{3}$ Therefore, a complete model must be able to predict this trend.

Figure 3 shows schematically the energy exchange processes, 
including conduction within the cell, enthalpy changes at the electrodes, and radiation heat exchange between the furnace and one control volume of the cell. The control volumes coincide with the flow model grid for scalar variables. Because the thickness of the cell is much smaller than its length, and the thermal conductivity is high, we assume the cell temperature is uniform along any perpendicular cross section and is a function of $x$ only, which is the distance from the cell leading edge. The energy balance over a control volume of dimensions $\Delta x$ and $\Delta y$ in the cell is formulated as

$$
\begin{aligned}
\rho_{s} c_{p, s} \frac{\partial T_{\text {cell }}}{\partial t} \Delta x \Delta y= & \left(q_{\text {left }}^{\prime \prime}+q_{\text {right }}^{\prime \prime}\right) \Delta y-i_{\text {tot }} \times E \times \Delta x+\left[(-\Delta H)_{a}\right. \\
& \left.+(-\Delta H)_{c}\right] \Delta x-\left(q_{R, a}^{\prime \prime}+q_{R, c}^{\prime \prime}\right) \Delta x
\end{aligned}
$$

where $\rho_{s}$ and $c_{p, s}$ are, respectively, the average density and specific heat capacity of the solid material in the control volume, $q_{\text {left }}^{\prime \prime}$ and $q_{\text {right }}^{\prime \prime}$ are, respectively, the conduction heat fluxes across the left and right faces, $i_{\text {tot }} \times E \times \Delta x$ is the power output to the external load, $\Delta H$ is the enthalpy change, and $q_{R}^{\prime \prime}$ is the net radiation heat flux to the furnace, with subscripts " $a$ " and " $c$ " indicating the anode and cathode, respectively. This formulation takes into account both ohmic heating in the electrolyte, and the heating due to the activation overpotentials, as may be verified by substituting Eq. 8 into Eq. 18. Radiation is modeled by

$$
q_{R}^{\prime \prime}=\sigma \varepsilon\left[T_{\text {cell }}^{4}(x)-T_{\text {furnace }}^{4}\right]
$$

where $\sigma$ is Stefan-Boltzmann's constant and $\varepsilon$ is the gray-body emissivity of the cell surface. The emissivity is often known only approximately; in our earlier work, we used it as a free parameter to match experimentally measured cell temperatures. ${ }^{16}$

The conduction-radiation model is described here for completeness, but for the calculations presented below it is not actually used. Instead, the simulations are done at constant temperatures, in order to decouple the effects of temperature from those due to other parameters. Readers are referred to our earlier work ${ }^{16}$ for the study of nonisothermal cases.

Among the submodels discussed above, the flow model, MIEC electrolyte model, and the conduction and radiation model are implemented in Fortran 90 using a CANTERA (Ref. 24) interface. The porous electrode transport model and the electrochemistry model are written in $\mathrm{C}++$ and also interfaced to CANTERA.

\section{Results and Discussion}

The model described here has been calibrated against experimental measurements, and predicted fuel cell performance agrees very well with experimental results. The reader is referred to our earlier work for more details. ${ }^{16}$ With such a detailed physical model, it is possible to examine the effects of different parameters on the overall SCFC performance, in a way that is nearly impossible from experiment alone, because effects that cannot be separated in reality can be turned on or off in a model. The insights into the underlying chemical and physical processes obtained in this way are the principal objective of modeling of this type. Here, we examine several aspects of SCFC operation. We first simulate a nominal SCFC with a YSZ electrolyte and Ni/YSZ anode. While this differs somewhat from SCFCs studied experimentally, it has the advantage that simulation parameters and catalytic reaction mechanisms are better known for this case than for others. We then examine the question of the optimal fuel to oxygen ratio, followed by an examination of the differences between using a purely ionically conducting electrolyte (YSZ) and one having mixed ionic-electronic conductivity (SDC). Finally, we examine various measures of efficiency for an SCFC and suggest possible approaches to improve the efficiency.

Simulation parameters. - The simulation geometry is shown in Fig. 2. The channel is taken to be $15 \mathrm{~mm}$ high and $135 \mathrm{~mm}$ long, and a uniform computational mesh of 21 cells (along the height) by 75 cells (along the length) is used for the channel flow. As seen in the results below, the perturbations to the flow field due to presence

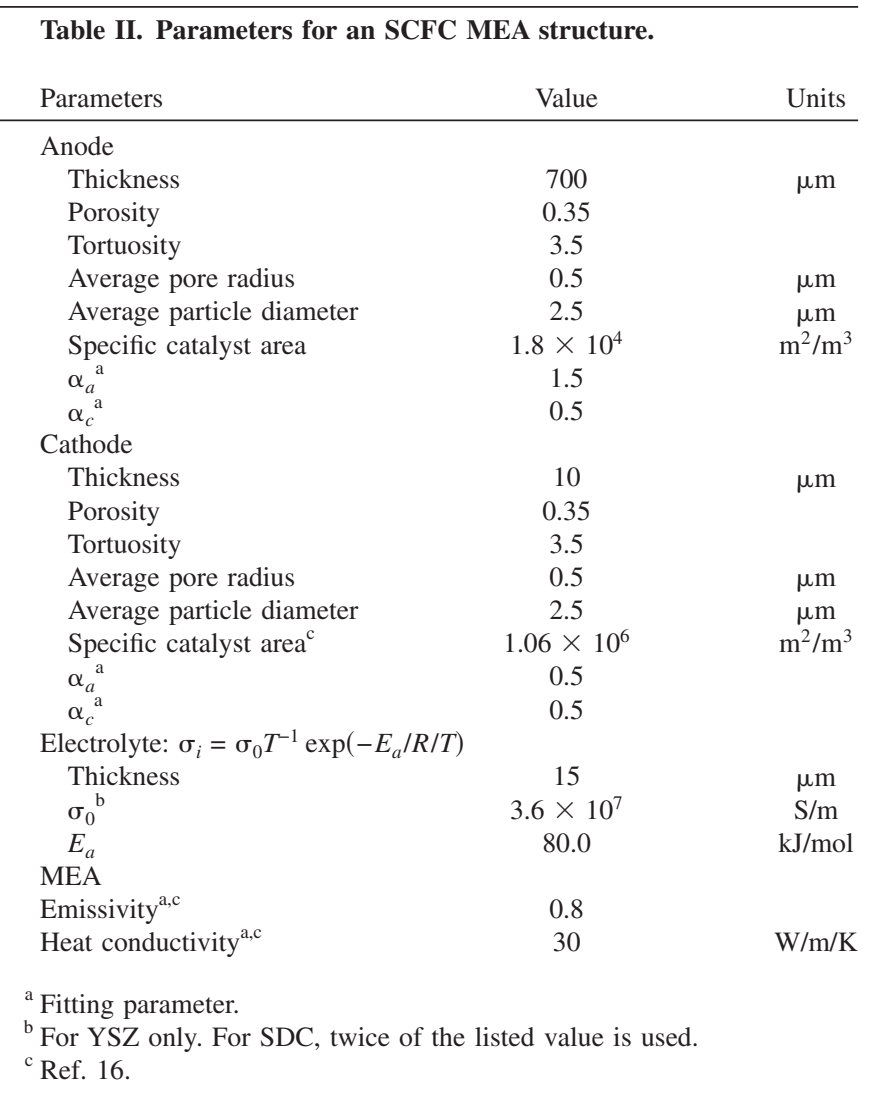

of the MEA do not extend to the edges of the simulation domain; therefore, the results are not sensitive to the choice of channel dimensions if the incoming flow velocity remains the same. For the simulations discussed below, a single MEA of length $12.6 \mathrm{~mm}$ and thickness $0.73 \mathrm{~mm}$ is placed horizontally in the channel, centered vertically and with the leading edge located at $25.2 \mathrm{~mm}$ from the entrance to the channel. The MEA is divided into seven segments (cells) of uniform lengths along the streamwise direction. The anode and cathode are divided into ten and eight control volumes in the $y$ direction, respectively. The electrolyte is not discretized.

A mixture of methane, oxygen, and helium is supplied at the left. Helium is used here as the diluent gas for consistency with our previous study, ${ }^{16}$ but the results with nitrogen would be similar, as discussed below. The molar flow rate of methane at the inlet is held fixed at $21.97 \mathrm{~mol} / \mathrm{m}^{2} / \mathrm{s}$, and the molar ratio of oxygen to helium is fixed at 1 to 4 .

The gas mixture is assumed to be fuel-rich, meaning that there is insufficient oxygen present for complete combustion of the fuel. This is consistent with how SCFC experiments have been carried out, ${ }^{1-3,5}$ and in fact is required for SCFC operation. For methane, stoichiometric combustion occurs for a $\mathrm{CH}_{4} / \mathrm{O}_{2}$ (volumetric) ratio of 0.5 . In the simulations discussed below, this ratio was varied from 0.5 to 5.0. A small amount of hydrogen and water is assumed to be present at the inlet at the beginning of the temporal integration, so that the equilibrium potential $E^{0}$ in Eq. 8 is well-defined. The feed rates of the two gases are reset to zero during the simulation when they are generated by the MEA.

The parameters that we use to describe the MEA structure are listed in Table II. All parameters are taken from Ref. 7 and 16. Since simulation results are performed at isothermal conditions, the emissivity and heat conductivity are not actually used.

Base case.- As a base case to which other results are compared below, we first consider an SCFC with a Ni/YSZ anode, a YSZ electrolyte, and a BSCF-SDC cathode. This cathode is used because 


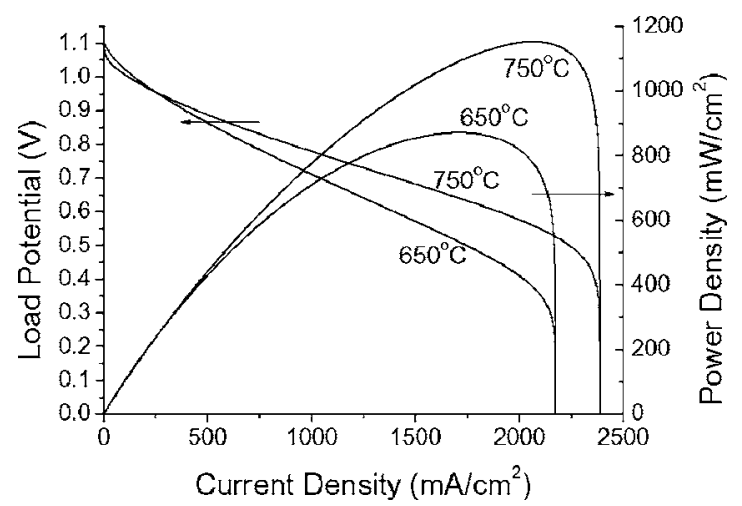

Figure 4. Simulated polarization curves of an SCFC with YSZ electrolyte at two different temperatures.

it was shown in Ref. 16 that its catalytic activity for methane oxidation is small under typical SCFC operating conditions.

The computed polarization curves for this cell at 650 and $750^{\circ} \mathrm{C}$ are shown in Fig. 4 for a $\mathrm{CH}_{4} / \mathrm{O}_{2}$ ratio of 1.0. The power density increases with temperature, as expected. The change in open-circuit voltage $(\mathrm{OCV})$ is unnoticeable. Transport limitation is observed for both cases near the short-circuit condition, and is more obvious at $750^{\circ} \mathrm{C}$. This limitation has also been reported by several groups. ${ }^{3,6,25}$ Our result shows that the limiting-current behavior depends on the gas flow rates. In this case, $\mathrm{H}_{2}$ at the anode-electrolyte interface is depleted near short-circuit, while $\mathrm{O}_{2}$ at the cathodeelectrolyte interface is still abundant. However, if the flow rate of oxygen is reduced by half, then $\mathrm{O}_{2}$ at the cathode becomes the limiting factor instead.

The OCV is defined as the load potential at which the total current is zero, and the simulated value is 1.09 and $1.06 \mathrm{~V}$ for 650 and $750^{\circ} \mathrm{C}$, respectively. Because no (or very little) hydrogen is present at the inlet, this voltage results from the hydrogen generated within the anode by catalytic reactions that proceed even at open circuit. Figure 5 shows the partial pressure of hydrogen and methane in the anode (along a cross section $6.3 \mathrm{~mm}$ from the fuel cell leading edge) as a function of the distance from the anode-electrolyte interface at $750^{\circ} \mathrm{C}$. The concentration of hydrogen gradually builds up as it gets closer to the interface, and remains high throughout the anode thickness. The hydrogen profile levels off at the interface because its consumption rate by electrochemistry is very small at open circuit.

At the OCV condition, we study the current distribution along the cell. Because the Nernst potential across the cell decreases along the flow direction due to the depletion of both fuel and oxygen, it must be true that at OCV condition, the current density is positive

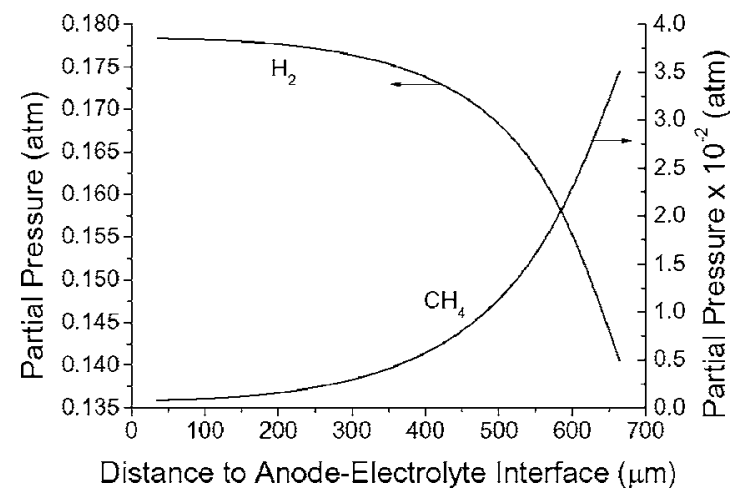

Figure 5. Partial pressure of $\mathrm{H}_{2}$ and $\mathrm{CH}_{4}$ vs distance to anode-electrolyte interface along a cross section $6.3 \mathrm{~mm}$ from the fuel cell leading edge; $750^{\circ} \mathrm{C} ; \mathrm{OCV}$ condition.

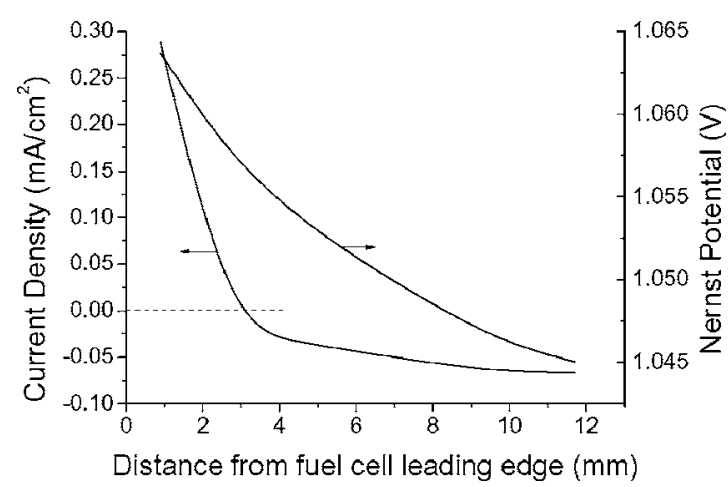

Figure 6. Distribution of local current density and Nernst potential along the cell at OCV condition.

for some locations and negative for others. This is verified by the computation results. The distribution of current density and Nernst potential at $\mathrm{OCV}$ along the cell at $750^{\circ} \mathrm{C}$ is shown in Fig. 6, and the partial pressures of $\mathrm{H}_{2}, \mathrm{H}_{2} \mathrm{O}$ at the anode-electrolyte interface and $\mathrm{O}_{2}$ at the cathode interface are plotted vs location along the fuel cell in Fig. 7. Despite the increase in hydrogen concentration along the cell, the Nernst potential decreases monotonically due to both the more rapid increase of water concentration on the anode side and the decrease of oxygen concentration on the cathode side (Eq. 10). Because current density is approaching zero at all locations at $\mathrm{OCV}$, the water must come from the catalytic oxidation of methane over the anode particle surfaces. A further inspection of the results shows that this reaction is predominantly full oxidation rather than partial oxidation of methane as widely claimed in experimental literature, and it only occurs within a very thin layer $(<10 \mu \mathrm{m})$ beneath the anodegas interface (this will be discussed in detail in a future publication). The concentration of water vapor along the anode-gas interface increases along the fuel cell surface in the streamwise direction due to convection of water vapor downstream by the channel flow as it diffuses out of the anode and accumulates in the stream, raising its concentration at the anode-electrolyte interface as well. The drop of oxygen partial pressure at the cathode-electrolyte interface has two causes. One is the full oxidation of methane over the catalytic surface, an unavoidable parasitic reaction for all SCFCs, and the other is the diffusion near the trailing edge of the fuel cell due to the more rapid depletion of oxygen on the anode side, which makes the oxygen partial pressure drop more rapidly near the end of the fuel cell where flows from both sides of the cell mix.

For the base case, simulated polarization curves with helium and nitrogen as the carrier gas at $750^{\circ} \mathrm{C}$ are shown in Fig. 8. It is obvious that on the low-current side, the change of carrier gas does not lead to any significant difference, but on the high-current side, trans-

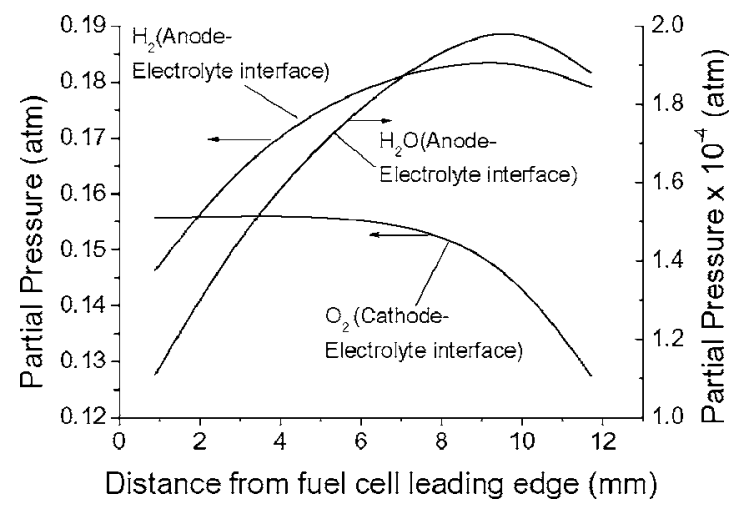

Figure 7. Distribution of $\mathrm{H}_{2}, \mathrm{H}_{2} \mathrm{O}$, and $\mathrm{O}_{2}$ partial pressures along the electrode-electrolyte interfaces at $750^{\circ} \mathrm{C}$ and $\mathrm{OCV}$ condition. 


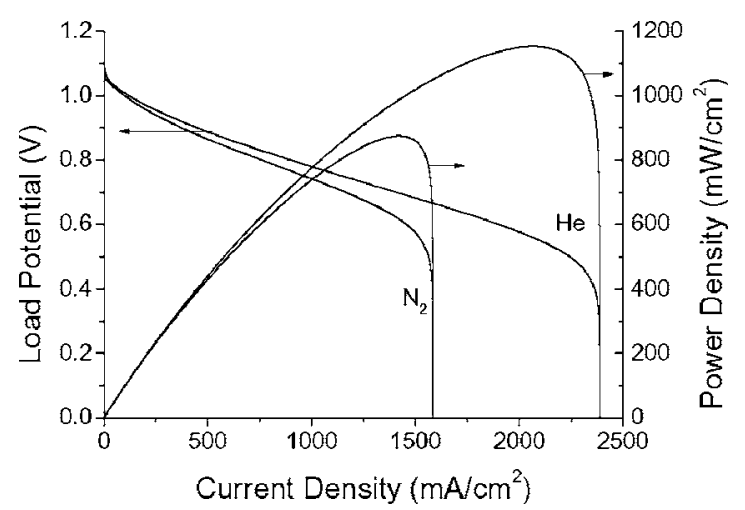

Figure 8. Simulated polarization curves of an SCFC with YSZ electrolyte at $750^{\circ} \mathrm{C}$ with different carrier gases.

port limit is reached at a much smaller current density for nitrogen. Comparatively, helium leads to a higher overall mass diffusion coefficient and thus results in improved performance, which is demonstrated by the higher peak power density. The OCV is not affected because electrochemical reactions are proceeding at very small rates and thus the transport of gas-phase species through the porous electrodes does not make any difference.

Effect of fuel-oxygen ratio.- A significant question of interest for SCFC operation is the optimal fuel-to-oxygen ratio. In this section, we explore this question in depth, beginning with the base case parameters of the last section, but varying the oxygen molar flow rate.

In this computation, the ratio is varied from 0.5 (stoichiometric combustion) to 5.0 , consistent with the fuel-rich requirement. The temperature is held at $750^{\circ} \mathrm{C}$ and the load potential is fixed at $0.5 \mathrm{~V}$, the voltage corresponding to the maximum power density for all cases.

The power density is plotted vs the $\mathrm{CH}_{4} / \mathrm{O}_{2}$ ratio in Fig. 9, and the optimum ratio (for maximum power) is found to be 1.67. While it is useful to know the precise value of the optimum $\mathrm{CH}_{4} / \mathrm{O}_{2}$ ratio, it is more instructive to understand the factors responsible for this result. To understand the dependence of power density on fuel-tooxygen ratio, we first plot the partial pressures of all the gas-phase species (directly obtained from the solution of the porous electrode transport model) at the anode-electrolyte interface, together with oxygen partial pressure at the cathode-electrolyte interface at the middle (in the streamwise direction) of the cell vs the $\mathrm{CH}_{4} / \mathrm{O}_{2}$ ratio (Fig. 10). When the ratio is close to stoichiometric (0.5), very little

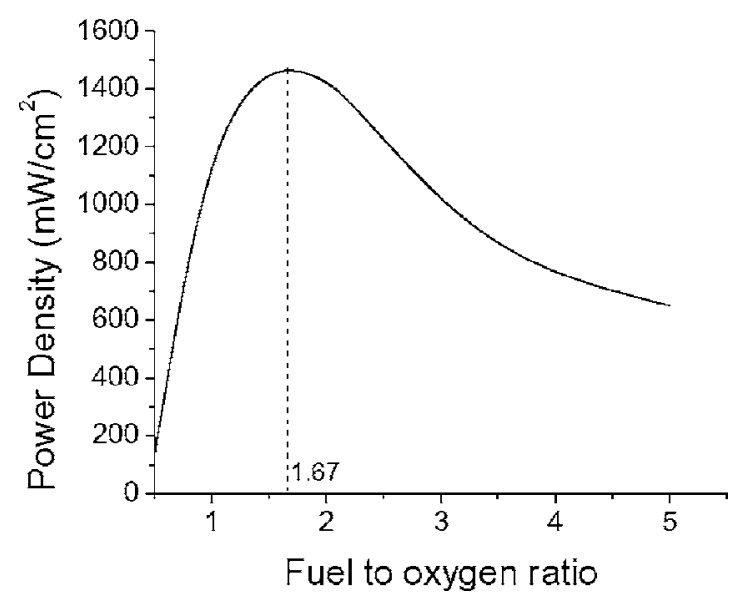

Figure 9. Simulated power density vs fuel-to-oxygen ratio at $750^{\circ} \mathrm{C}$ and load potential of $0.5 \mathrm{~V}$; YSZ electrolyte.

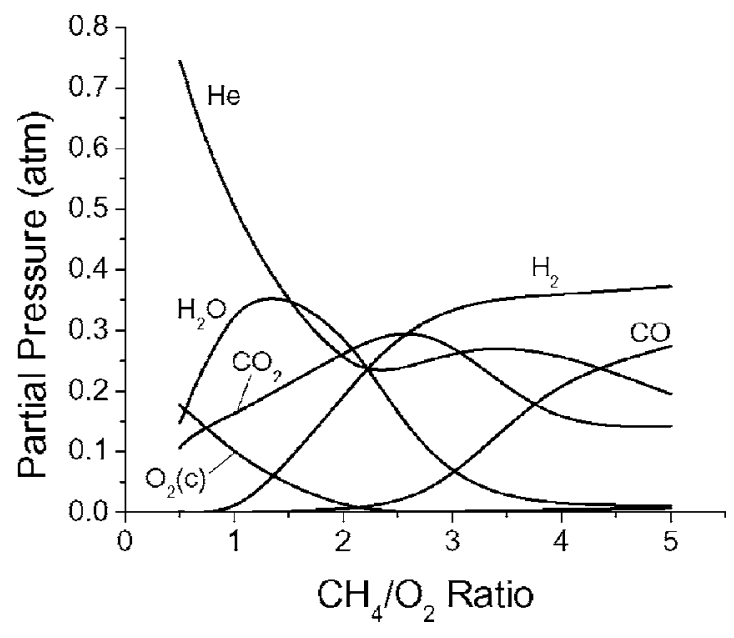

Figure 10. Partial pressure of gas-phase species at the anode-electrolyte interface (plus $\mathrm{O}_{2}$ at cathode-electrolyte interface) at the middle (along $x$ direction) of the fuel cell $\left(\mathrm{CH}_{4}\right.$ and $\mathrm{O}_{2}$ are too low to show); $T=750^{\circ} \mathrm{C}$; load potential is $0.5 \mathrm{~V}$.

hydrogen is generated in the anode because most methane that penetrates into the anode is fully catalytically oxidized. When the ratio is over 2.0, although abundant hydrogen is generated in the anode (and diffuses to the anode-electrolyte interface), the oxygen concentration on the cathode side is reduced due to both the low oxygen flow rate and the increased concentration of $\mathrm{H}_{2}$ and $\mathrm{CO}$ transported from the anode side, which consume oxygen through their full oxidation (in addition to the full oxidation of methane) over the cathode catalyst surface. Because in this model it is hydrogen that is the electrochemically active fuel species, and in addition oxygen is required for the cathode reaction to take place, both must be present (in the anode and cathode, respectively) for a current to flow; the optimal fuel-to-oxygen ratio is the one that simultaneously results in adequate hydrogen at the anode and oxygen at the cathode.

Due to the coupling of many physical and chemical processes, the optimum fuel-to-oxygen ratio cannot be determined by simply assuming either full oxidation of the fuel (for maximum enthalpy change) or partial oxidation of the fuel (for the highest yield of $\mathrm{H}_{2}$ ). Because it is the concentrations of $\mathrm{H}_{2}$ and $\mathrm{O}_{2}$ at the electrodeelectrolyte interfaces that ultimately determine the fuel cell power, the optimum $\mathrm{CH}_{4} / \mathrm{O}_{2}$ ratio, defined by the flow rates of the gas feed at peak power condition, has to be determined by considering all possible processes that influence the conversion of fuel to $\mathrm{H}_{2}$ in the anode and the transport of contributing gas-phase species in both the electrodes and the gas channel, as well as electrochemistry at electrode-electrolyte interfaces. The parameters describing these processes include, but may not be limited to temperature, electrode catalyst activity, electrode microstructure, flow geometry, and exchange current density.

Flow geometry (including MEA orientation and flow-field dimensions) is probably the most sensitive factor for the optimum ratio and SCFC electrical performance. It influences local power density along the MEA (and thus the optimum $\mathrm{CH}_{4} / \mathrm{O}_{2}$ ratio) because convection and transport determine the distribution of reactants around the MEA. Because the distribution of power density depends on location along the MEA, the optimum ratio of 1.67 can be interpreted as a value at which the pointwise average power density of the fuel cell is the highest. However, not all locations of the fuel cell achieve their maximum power simultaneously. Figure 11 shows the contour plot of the local current density vs $\mathrm{CH}_{4} / \mathrm{O}_{2}$ ratio and location on the MEA. The optimum ratio is found to decrease with distance from the leading edge because, according to the simulation results, oxygen is consumed faster (by moles) than methane due to the coexistence of partial and full oxidation of methane in the anode, so that the gas mixture becomes increasingly fuel-rich as 


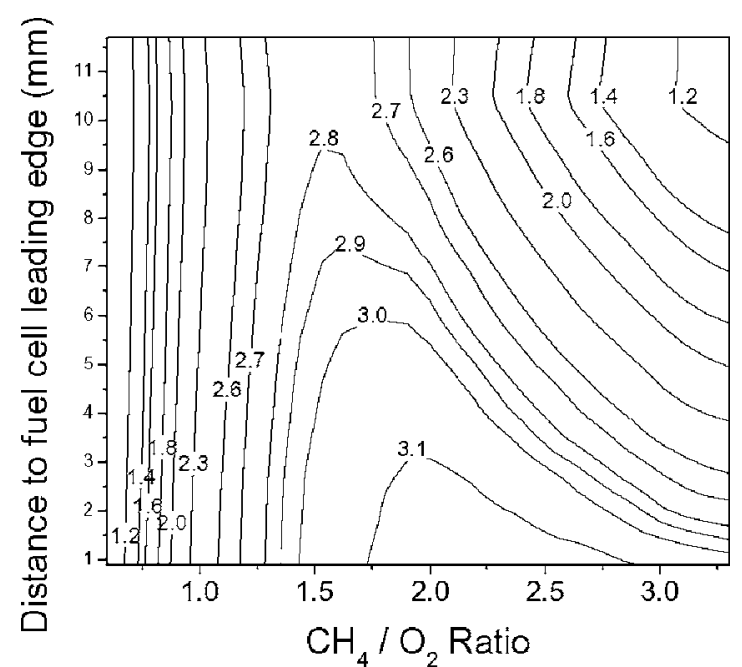

Figure 11. Contour plot of local current density vs $\mathrm{CH}_{4} / \mathrm{O}_{2}$ ratio and location on the MEA at $750^{\circ} \mathrm{C}$ and load potential of $0.5 \mathrm{~V}$.

it flows along the MEA. Therefore, at a downstream location, a higher oxygen flow rate is needed at the inlet than at an upstream location, so that the optimum fuel-to-oxygen ratio goes down along the flow direction.

The optimum ratio and MEA performance can be enhanced by reorienting the MEA without changing any other parameter. To achieve this, more understanding about the coupling between different parts of the MEA through the external gas flow is needed. In the geometry with the MEA being parallel to the channel axis, the upstream cells of the MEA has a strong influence on the downstream ones, but not vice versa. This is verified by Fig. 12, which shows for different MEA lengths (with the leading edge fixed), the current density distribution along the MEA at flow rates $\mathrm{CH}_{4}: \mathrm{O}_{2}: \mathrm{He}$ $=1: 1: 4$. We see that, except the last two cells of each MEA, the power density at other locations almost falls on the same curve, indicating that flow convection downstream is much stronger than backward diffusion. The current density of the last two cells of each MEA is elevated because the unconsumed methane and oxygen that bypass the MEA on both sides mix at the trailing edge. For the same reason, the optimum $\mathrm{CH}_{4} / \mathrm{O}_{2}$ ratio of each cell along the MEA shows a similar trend in Fig. 13. For a better understanding of the one-way influence, the two-dimensional distribution (mole fractions) of gas-phase species in the gas chamber is shown in Fig. 14. From the figures, we infer that, because of the depletion of oxygen by upstream cells, flow geometries that improve the oxygen distri-

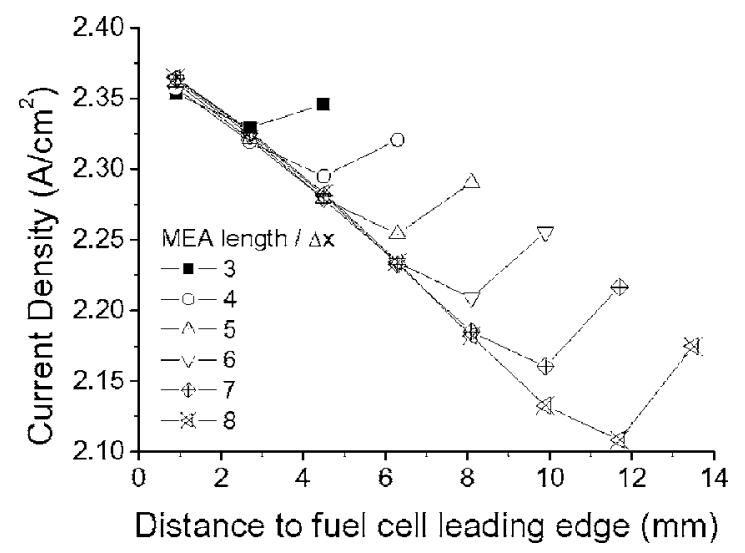

Figure 12. Current density along the MEA for different MEA lengths; flow rate $\mathrm{CH}_{4}: \mathrm{O}_{2}: \mathrm{He}=1: 1: 4$.

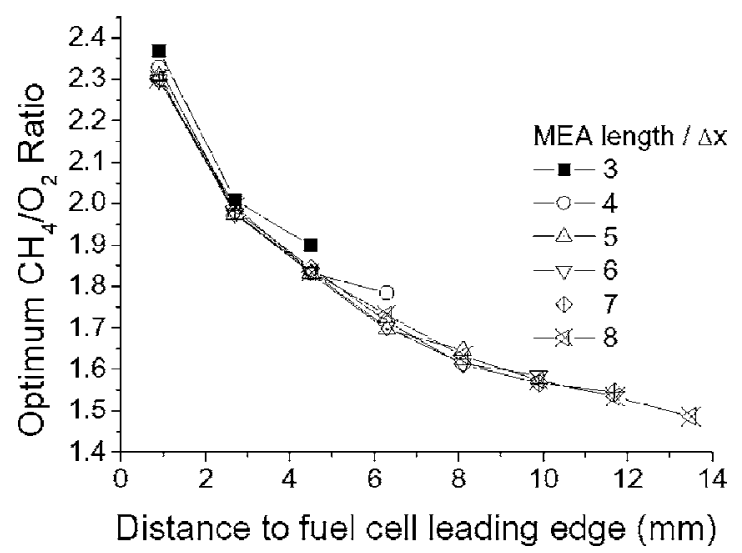

Figure 13. Optimum fuel-to-oxygen ratio of each cell along the MEA for different MEA lengths; $\Delta x$ : $x$-dimension of one computation grid.

bution over the MEA surface could have a higher optimum ratio and a better electrical performance. In our previous work, ${ }^{16}$ we demonstrated that the fuel cell performance could be improved by simply reorienting the MEA. Here, a similar effect can be shown for the optimum ratio. When the MEA is oriented such that the cathode is facing the fresh gas feed, the optimum ratio would increase to 2.5 according to our computation.

Meanwhile, temperature and electrochemistry will influence the rates and equilibrium of the catalytic reactions, and so will influence the optimum ratio as well. Our results show that in the range of 650 to $750^{\circ} \mathrm{C}$, the ratio decreases monotonically with temperature. The exchange current density of the anode has little influence, but that of the cathode could increase this ratio by $35 \%$ (to 2.2) when it is lowered by 2 orders of magnitude, indicating that the electrochemical properties of the cathode material might be a more important consideration in cell design. Furthermore, the catalytic activity and structural parameters of the electrodes (e.g., thickness, porosity, and pore size) jointly dictate the distribution of reactants and products within the electrodes, and thus eventually the concentration of $\mathrm{H}_{2}$ at the anode-electrolyte interface and $\mathrm{O}_{2}$ at the cathodeelectrolyte interface. So, they are also expected to be partly responsible. This will be addressed in a future publication about parameter optimization of SCFC design.

Effects due to MIEC electrolytes. - In the third example, we compute the polarization curve of the SCFC with an SDC electrolyte at $650^{\circ} \mathrm{C}$. All parameters except the ionic conductivity are the same as listed in Table II. Earlier in this paper, we compared ionic resistivities of different electrolyte materials and indicated the superiority of MIEC electrolytes over pure ionic-conductor ones. As a good approximation and for the purpose of qualitative comparison, we assume that the ionic conductivity of SDC is twice that of YSZ, while the electronic current is calculated by Eq. 16. The $I-V$ curves for SDC and YSZ electrolytes are compared in Fig. 15. Due to the higher ionic conductivity of SDC, the peak power density is improved by almost $40 \%$. The trend shown in this figure is the same as the results in Ref. 4. However, near short-circuit condition, serious transport limitation occurs for the SDC cell, indicating that the electrode (especially the anode, because it is much thicker than the cathode) structural parameters in Table II lead to significant masstransfer overpotential that needs to be reduced for the improvement of SCFC performance. Therefore, we increase the porosity of the anode from 0.35 to 0.5 , and as expected, transport limitation is attenuated. The peak power density and short-circuit current are improved by 5 and $11 \%$, respectively. This is because the increase of porosity makes it easier for reactants to diffuse to the surface reaction sites within the anode and for hydrogen produced by partial oxidation and reforming reactions to diffuse to the anode-electrolyte interface. By the same reasoning, reducing the anode thickness 


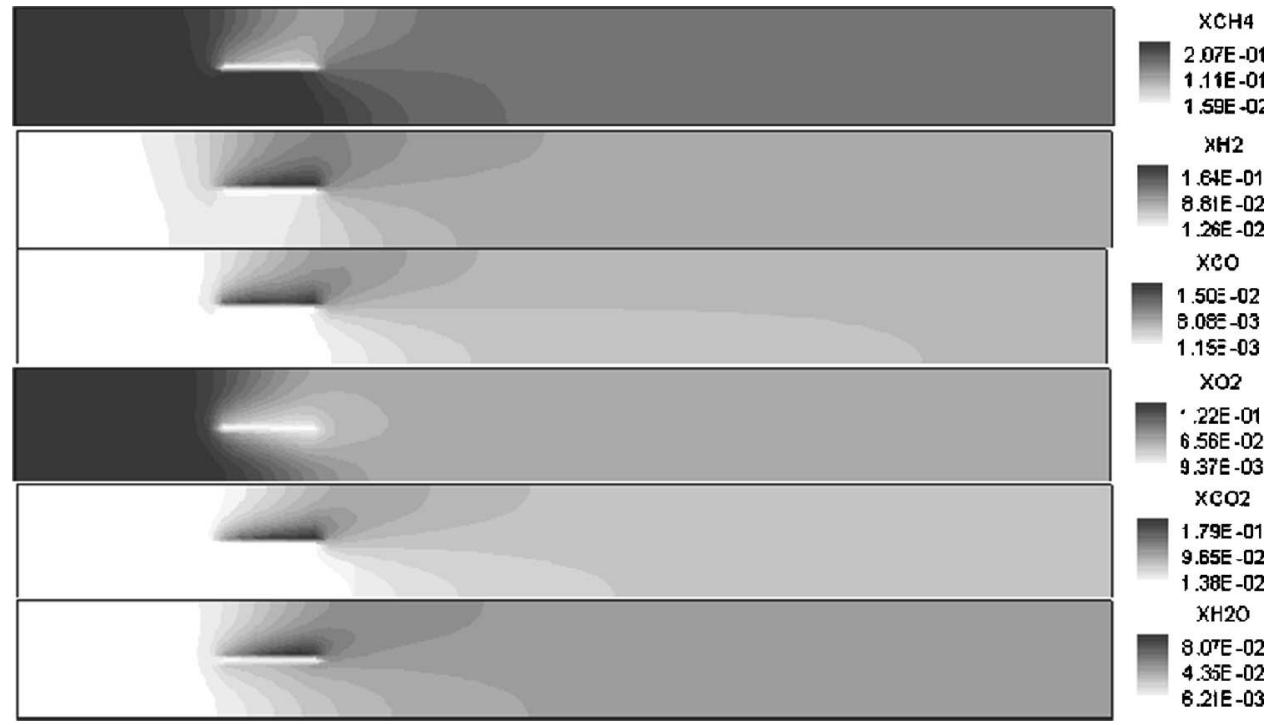

Figure 14. Two-dimensional distribution of gas-phase components in the gas chamber at optimum fuel-to-oxygen ratio. could have the same benefit. This has been discussed in our previous work. ${ }^{16}$ The OCV of the SDC cell is only $0.85 \mathrm{~V}$ due to mixed conductivity, considerably lower than the YSZ cell. Despite this, the improvement in power density manifests the advantage of using SDC as electrolyte in SCFC design.

In spite of the improvement in power density and reduction in operating temperature compared with conventional dual-chamber SOFCs, the efficiency and fuel utilization of the SCFCs simulated are still low. The fuel cell efficiency is defined as

$$
\eta=\frac{W_{e}}{\dot{m}_{f, \text { in }} \Delta h_{\text {in }}}
$$

where $W_{e}$ is the electrical power output of the fuel cell, $\dot{m}_{f, \text { in }}$ is the fuel mass flux at the inlet, and $\Delta h_{\text {in }}$ is the enthalpy released by completely oxidizing the fuel (i.e., combustion heat). The fuel utilization efficiency is defined as

$$
\varepsilon_{U}=1-\frac{\dot{m}_{f, \text { out }} \Delta h_{\text {out }}}{\dot{m}_{f, \text { in }} \Delta h_{\text {in }}}
$$

where $\dot{m}_{f \text {,out }}$ is the mass flux of the fuel at the channel outlet and $\Delta h_{\text {out }}$ is the heating value associated with completely oxidizing the exhaust flow. In this example, we use the lower heating value (LHV) of methane and other fuels $\left(\mathrm{H}_{2}, \mathrm{CO}\right)$ to define $\eta$ and $\varepsilon_{U}$. The LHV is defined as the amount of heat produced by the complete combus-

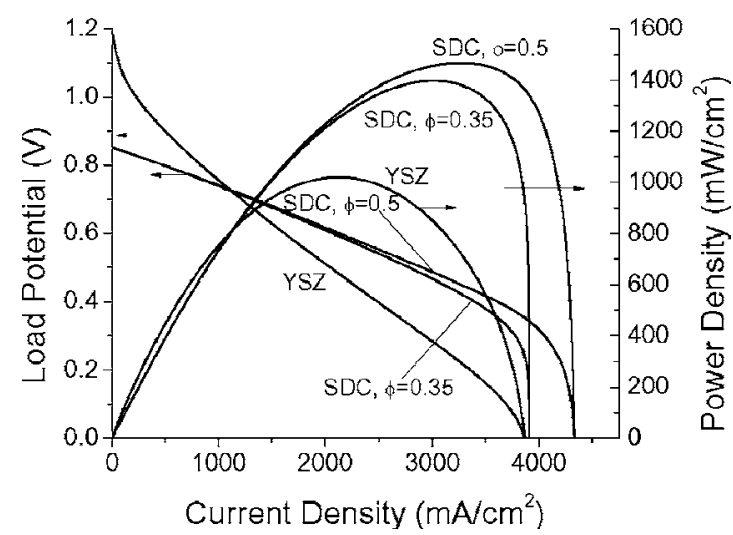

Figure 15. Comparison of simulated polarization curves of SCFC with SDC electrolyte (two different anode porosities, $\phi=0.35$ and 0.5 ) and YSZ electrolyte; the ionic conductivity of SDC is twice that of YSZ. tion of a unit quantity of fuel when the water in the product is in a vapor form. Because the LHV of the inlet fuel is irrelevant to the operating conditions of the fuel cell, $\eta$ changes in the same way as $W_{e}$ does. For the polarization curves simulated in the last example, the maximum efficiency for fuel cells with YSZ and SDC electrolyte is $2.5 \%$ (at $0.5 \mathrm{~V}$ ) and $3.4 \%$ (at $0.4 \mathrm{~V}$ ), respectively.

In contrast, the fuel utilization depends on voltage in a very similar manner as the current does. As shown in Fig. 16, fuel utilization efficiency $\varepsilon_{U}$ decreases monotonically with load potential. The similarity is because the consumption rate of hydrogen by electrochemistry at the anode-electrolyte interface strongly influences the conversion of methane by partial oxidation, reforming, and water-gas shift reactions. To better understand this relationship, it is meaningful to explore the conversion of methane to other products relevant to the load potential. First, we define the yield percentage and selectivity percentage of species. The yield of species $k$ is the ratio of the total amount of product $k$ to the initial amount of reactant; the selectivity of species $k$ is the ratio of the total amount of product $k$ to the total amount of product of interest. Both percentages need to be calculated based on the balance (conservation) of one element that the species contains (which in our case could be $\mathrm{C}$, $\mathrm{H}$, or $\mathrm{O}$ ). So, if we look at the yield and selectivity percentage (calculated at the outlet of the flow channel) of the products including $\mathrm{CO}, \mathrm{CO}_{2}, \mathrm{H}_{2}$, and $\mathrm{H}_{2} \mathrm{O}$ in Fig. 17 and 18, we see that at shortcircuit condition, reacted methane is almost uniformly converted to $\mathrm{CO}_{2}$ because the consumption rate of hydrogen by electrochemistry

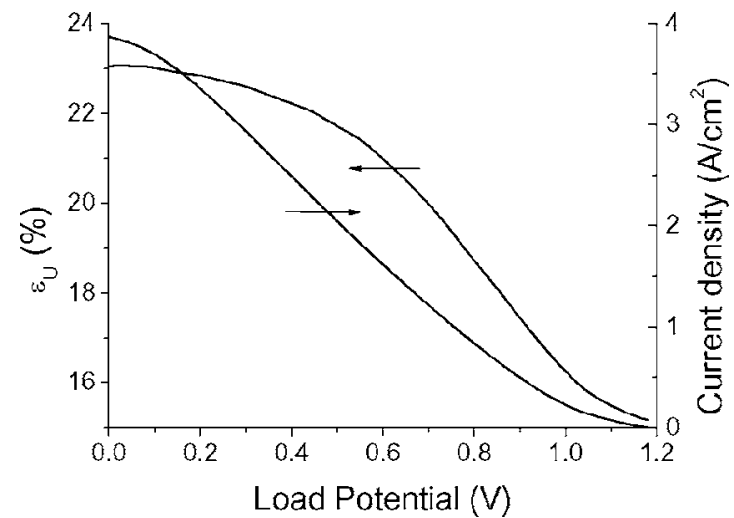

Figure 16. Fuel utilization $\varepsilon_{U}$ and current density as functions of load potential. 


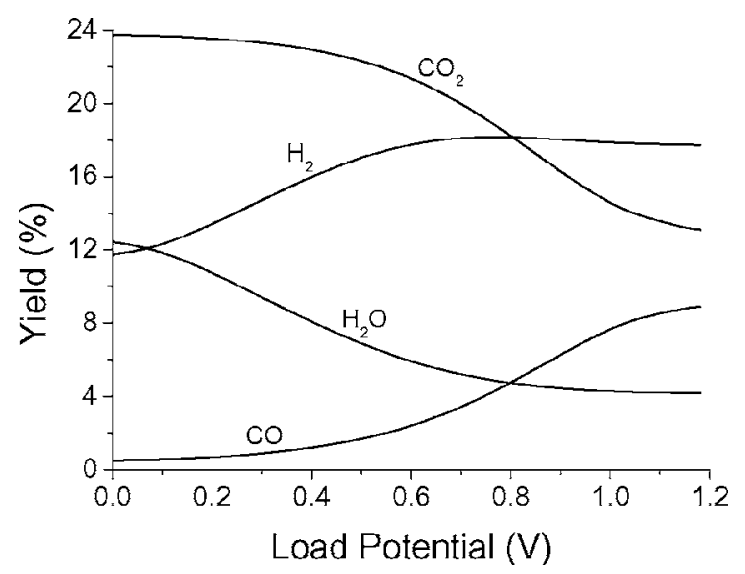

Figure 17. Yield percentage of gas-phase product species as functions of load potential. $\mathrm{CO}$ and $\mathrm{CO}_{2}$ are based on $\mathrm{C}$ balance; $\mathrm{H}_{2}$ and $\mathrm{H}_{2} \mathrm{O}$ are based on $\mathrm{H}$ balance.

is the highest. As a result, water concentration is the highest while hydrogen concentration is the lowest (compared with their concentrations at other voltages). At open-circuit condition, however, although very little hydrogen is consumed by electrochemistry, the fuel utilization is still $15 \%$. This is because the catalytic reactions mentioned above are still occurring within the porous nickel anode. Because no hydrogen is consumed by electrochemistry, the water must be generated by (direct or equivalent) full oxidation of methane. Meanwhile, both $\mathrm{H}_{2}$ and $\mathrm{CO}$ reach their maximum, indicating that the reaction rates of methane reforming and water-gas shift reaction are still high.

Although the efficiency and fuel utilization are low for one fuel cell, they can be improved by increasing the number of fuel cells. For the MEA with YSZ electrolyte, two more MEAs identical to the first one are placed downstream along the channel axis. The distance between each two adjacent MEAs is the same as the MEA length. A load potential of $0.5 \mathrm{~V}$ is applied to all MEAs. We find that, similar to example 2, the power output of the first MEA is not influenced noticeably by the two cells downstream, but the performance of each downstream MEA is strongly overshadowed by the upstream one(s). The contribution from the downstream cells significantly improves the total power output. The overall efficiency increases from 2.5 to $5.5 \%$, and fuel utilization goes up from 22 to $43 \%$.

In general, based on our simulations, both $\eta$ and $\varepsilon_{U}$ can be enhanced by improving the total power output, which depends on the optimization of both single-cell components and the SCFC sys-

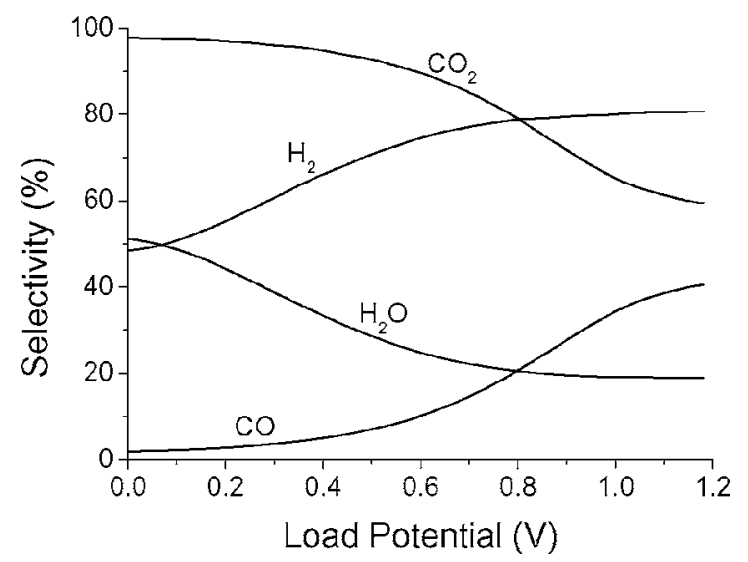

Figure 18. Selectivity percentage of gas-phase product species as functions of load potential. $\mathrm{CO}$ and $\mathrm{CO}_{2}$ are based on $\mathrm{C}$ balance; $\mathrm{H}_{2}$ and $\mathrm{H}_{2} \mathrm{O}$ are based on $\mathrm{H}$ balance.

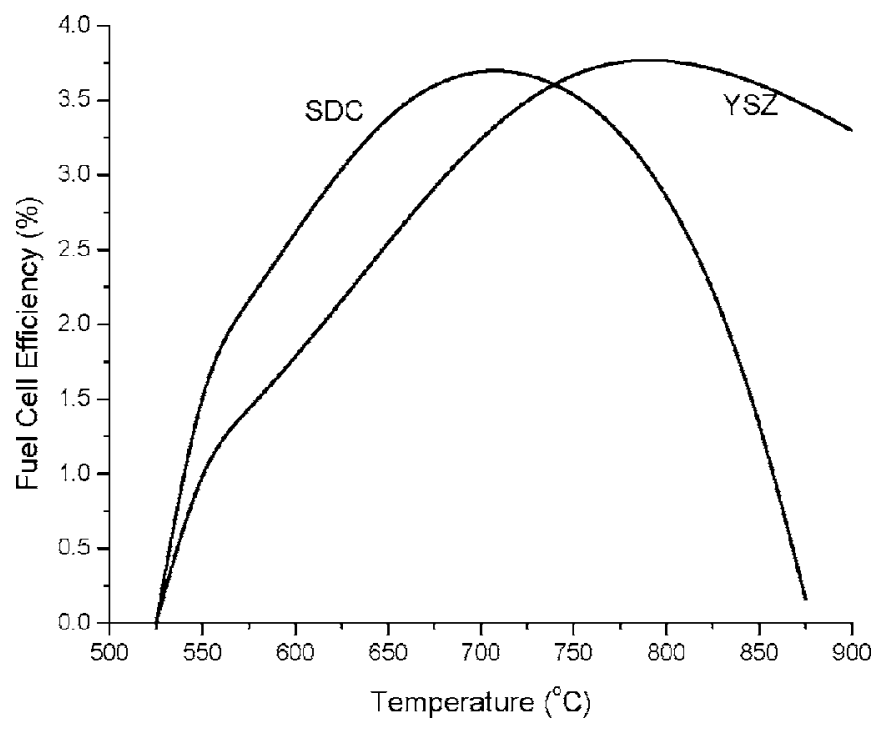

Figure 19. Maximum efficiency of an SCFC with SDC electrolyte or YSZ electrolyte as a function of temperature; load potentials for SDC cell and YSZ cell are 0.4 and $0.5 \mathrm{~V}$, respectively.

tem design. For a single cell, thicknesses of the electrode and electrolyte, catalytic activity of the electrodes, and ionic conductivities of the electrolyte are important considerations. Besides these wellknown facts, the microstructure of the electrodes is also worth attention. Structures that favor anode-side hydrogen production and cathode-side oxygen reduction (e.g., high specific surface area), as well as those that reduce the diffusion path of hydrogen and oxygen to the anode-electrolyte and cathode-electrolyte interfaces (e.g., high porosity, small electrode thickness, etc.) will lead to increase in power output, efficiency, and fuel utilization.

On the system design level, besides increasing the number of MEAs (i.e., using stacks), one can also improve the overall performance by carefully managing the flow geometry (e.g., MEA orientation, channel width and shape, gaps between MEAs) and controlling the gas flow rates and operating temperature. Flow geometry is probably the most important consideration in system optimization design, because it can significantly reduce the amount of fuel and oxygen that bypasses the MEAs, improve the distribution of reactants around the MEA, and minimize the harmful parasitic reactions that keep the fuel and oxygen from being efficiently used (e.g., oxidation of $\mathrm{CO}$ and $\mathrm{H}_{2}$ at the cathode).

Temperature could also lead to improvement of fuel cell efficiency, but it must be controlled carefully. Although a higher temperature promotes reaction rates of both catalytic chemistry and electrochemistry, it does not always benefit the power output and fuel cell efficiency, because the catalytic selectivity of both electrodes can be impaired by high temperatures. Moreover, for SCFCs with SDC electrolyte, high temperature drastically drives up the reverse electronic current and so is not favorable for the power output either. To show this, we simulate the efficiency of SCFCs with SDC and YSZ electrolytes in the range of 500 to $900^{\circ} \mathrm{C}$ with flow rates $\mathrm{CH}_{4}: \mathrm{O}_{2}: \mathrm{He}=1: 0.6: 2.4$. The results are shown in Fig. 19. For both cases, the load potentials are fixed but at different values (0.4 V for SDC; $0.5 \mathrm{~V}$ for YSZ), so that the maximum power output could be achieved at each temperature. The diagram shows that the SDC cell has the best efficiency of $3.7 \%$ around $710^{\circ} \mathrm{C}$, while the YSZ cell reaches its maximum of $3.8 \%$ around $790^{\circ} \mathrm{C}$. The peak of the SDC curve shifts about $80^{\circ} \mathrm{C}$ to the left due to the increase of the reverse electronic current with temperature, which also accounts for the faster drop of the SDC curve at high temperatures (i.e., above $750^{\circ} \mathrm{C}$ ). At $525^{\circ} \mathrm{C}$, both efficiencies go down to zero because the temperature is too low to sustain the catalytic reactions in the anode. The result shows that, for each type of electrolyte, there is an opti- 
mum temperature range for the best performance of the cell. Cells with an MIEC electrolyte should generally be operated in a lower temperature range (without a loss in performance) due to the reverse electronic current. The temperature range for the SDC cell to achieve better than half of its peak efficiency is approximately $560-840^{\circ} \mathrm{C}$, and that for the $\mathrm{YSZ}$ cell is higher by $50^{\circ} \mathrm{C}$ or more.

According to their definitions, $\eta$ and $\varepsilon_{U}$ could also be improved by reducing the amount of fuel that comes into the system. However, this shifts more challenges to flow management-geometrical design and might be more difficult to achieve because both fuel and oxygen could be depleted more quickly along the MEA, resulting in a decrease in the total power output. In particular, for SCFC stacks with SDC electrolyte, the depletion of oxygen by upstream cells will lead to extremely low oxygen partial pressure at the cathodeelectrolyte interface. As a result, the reverse electronic current is extraordinarily high and the total power output is seriously reduced. If $\eta$ and $\varepsilon_{U}$ could be maintained or improved with a lower fuel flow rate, it is critical to match the spatial velocity of the flow field around the MEA to that prior to the change, because the flow field determines the distribution of gas-phase species over the whole interface between the MEA and the gas flow. This can possibly be achieved by reducing the channel diameter or increasing the flow rate of the carrier gas.

For $\eta$ and $\varepsilon_{U}$ defined by Eq. 20 and 21, one can also base the definitions on the higher heating value (HHV) of the fuels, in which the potential heat of water vapor is considered. We find that for the cases discussed above, HHV-based $\eta$ is approximately one-third of the LHV-based one, while $\varepsilon_{U}$ is almost the same for both cases.

\section{Conclusions}

A two-dimensional model for single-chamber SOFCs operating on hydrocarbon fuels has been developed. It provides insights into factors responsible for SCFC performance. The model is able to simulate the operation of SCFC with various geometries and under various operating conditions. It is also able to simulate SCFC (systems) operating on many kinds of hydrocarbon fuels as long as the corresponding mechanism for partial oxidation and reforming reactions is available.

Four examples based on parameters from the literature are discussed to address some important issues in SCFC optimization design, including optimum fuel-to-oxygen ratio, electrolyte material, flow geometry, fuel cell efficiency, and fuel utilization. The optimum fuel-to-oxygen ratio depends on many factors, and we find that flow geometry is probably the most important one. By managing the flow field, the optimum fuel-to-oxygen ratio and the maximum power output can both be improved. With the model's capability of simulating mixed conductivity, we have shown that the SDC electrolyte delivers much better performance than YSZ in the temperature range of $650-750^{\circ} \mathrm{C}$. The efficiency of an SCFC strongly depends on temperature, and the optimum range for SDC-electrolyte cell is approximately 560 to $840^{\circ} \mathrm{C}$. The efficiency and fuel utilization of a single-MEA SCFC are very low, but can be improved by using MEA stacks, optimizing the MEA material properties and microstructure, improving the flow-field geometry, and controlling operating conditions.
However, because the model is only two-dimensional, it probably cannot capture some three-dimensional effects that might be important for the operation of SCFC systems. But, it does provide insights into many important mechanistic issues and is sufficient for at least qualitatively describing and understanding most of the important processes. The trends predicted by the model are more important than precise numerical values and will serve as a useful basis for experimental designs.

\section{Acknowledgments}

This work was partly supported by the Defense Advanced Research Projects Agency (DARPA) under grant N66001-01-1-8966 and partly by the Office of Naval Research under grant N00014-051-0339. We greatly appreciate the constructive suggestions from S. M. Haile, Z. Shao, C. Pantano, W. Lai, and J. Mederos.

California Institute of Technology assisted in meeting the publication costs of this article.

\section{References}

1. T. Hibino, A. Hashimoto, M. Yano, M. Suzuki, S. Yoshida, and M. Sano, J. Electrochem. Soc., 149, A133 (2002).

2. Z. Shao, S. M. Haile, J. Ahn, P. D. Ronney, Z. Zhan, and S. A. Barnett, Nature (London), 435, 795 (2005)

3. Z. Shao, C. Kwak, and S. M. Haile, Solid State Ionics, 175, 39 (2004)

4. T. Hibino, A. Hashimoto, T. Inoue, J. Tokuno, S. Yoshida, and M. Sano, J. Elec trochem. Soc., 147, 2888 (2000).

5. T. Hibino, A. Hashimoto, T. Inoue, J. Tokuno, S. Yoshida, and M. Sano, J. Elec trochem. Soc., 148, A544 (2001)

6. A. Tomita, D. Hirabayashi, T. Hibino, M. Nagao, and M. Sano, Electrochem. SolidState Lett., 8, A63 (2005).

7. H. Zhu, R. J. Kee, V. M. Janardhanan, O. Deutschmann, and D. G. Goodwin, J. Electrochem. Soc., 152, A2427 (2005).

8. R. J. Kee, H. Zhu, and D. G. Goodwin, in Proceedings of 30th International Symposium on Combustion, Chicago, IL (2004).

9. G. K. Gupta, E. S. Hecht, H. Zhu, A. M. Dean, and R. J. Kee, J. Power Sources, 156, 434 (2006).

10. K. M. Walters, A. M. Dean, H. Zhu, and R. J. Kee, J. Power Sources, 123, 182 (2003).

11. K. Nerinckx, J. Vierendeels, and E. Dick, J. Comput. Phys., 206, 597 (2005).

12. S. V. Patankar, Numerical Heat Transfer and Fluid Flow, Hemisphere Publishing Corporation, Bristol, PA (1980)

13. E. A. Mason and A. P. Malinauskas, in Gas Transport in Porous Media: The Dusty-Gas Model, American Elsevier, New York (1983).

14. T. Thampan, S. Malhotra, H. Tang, and R. Datta, J. Electrochem. Soc., 147, 3242 (2000)

15. E. S. Hecht, G. K. Gupta, H. Zhu, A. M. Dean, R. J. Kee, L. Maier, and O. Deutschmann, Appl. Catal., A, 295, 40 (2005).

16. Y. Hao, Z. Shao, J. Mederos, W. Lai, D. G. Goodwin, and S. M. Haile, Solid State Ionics, 177, 2011 (2006).

17. P. J. Gellings, Editor, with H. J. Bouwmeester, in CRC Handbook of Solid State Electrochemistry, p. 451, CRC Press, Boca Raton, FL (1997).

18. J. Kim, A. V. Virkar, K. Z. Fung, K. Mehta, and S. C. Singhal, J. Electrochem. Soc., 146, 69 (1999).

19. I. Riess, Solid State Ionics, 157, 1 (2003).

20. I. Riess, J. Phys. Chem. Solids, 47, 129 (1986).

21. I. Riess, M. Gödickemeier, and L. J. Gauckler, Solid State Ionics, 90, 91 (1996).

22. M. Gödickemeier and L. J. Gauckler, J. Electrochem. Soc., 145, 414 (1998)

23. W. Lai and S. M. Haile, J. Am. Ceram. Soc., 88, 2979 (2005).

24. D. G. Goodwin, in Chemical Vapor Deposition XVI and EUROCVD 14, M. Allendorf, F. Maury, and F. Teyssandier, Editors, PV 2003-08, p. 155, The Electrochemical Society Proceedings Series, Pennington, NJ (2003); see also 〈http:// www.cantera.org $\rangle$

25. X. Jacques-Bédard, T. W. Napporn, R. Roberge, and M. Meunier, J. Power Sources, 153, 108 (2006). 